\title{
Molecular Genetic Techniques in Biomarker Analysis Relevant for Drugs Centrally Approved in Europe
}

\author{
Tatjana Huebner $^{1}$ (1) $\cdot$ Michael Steffens $^{1} \cdot$ Catharina Scholl $^{1}$
}

Accepted: 18 November 2021 / Published online: 14 December 2021

(c) The Author(s) 2021

\begin{abstract}
On the basis of scientific evidence, information on the option, recommendation or requirement to test for pharmacogenetic or pharmacogenomic biomarkers is incorporated in the Summary of Product Characteristics of an increasing number of drugs in Europe. A screening of the Genetic Testing Registry (GTR) showed that a variety of molecular genetic testing methods is currently offered worldwide in testing services with regard to according drugs and biomarkers. Thereby, among the methodology indicated in the screened GTR category 'Molecular Genetics', next-generation sequencing is applied for identification of the largest proportion of evaluated biomarkers that are relevant for therapeutic management of centrally approved drugs in Europe. However, sufficient information on regulatory clearances, clinical utility, analytical and clinical validity of applied methods is rarely provided.
\end{abstract}

\section{Key Points}

For the analysis of a majority of biomarkers relevant for prescriptions of approved drugs in Europe, next-generation sequencing services are generally offered.

The speed of developments with regard to biomarker research and emerging techniques for pharmacogenomic testing presents a challenge to standardization and regulation in the use of companion diagnostics.

\section{Introduction}

The interindividual variability in drug response is affected by inherited and non-inherited genomic alterations. These alterations can modify pharmacokinetics or pharmacodynamics of drugs and thus affect efficacy and safety of drug therapy [1]. According to the state of scientific evidence on

Tatjana Huebner

Tatjana.Huebner@bfarm-research.de

1 Research Division, Federal Institute for Drugs and Medical Devices (BfArM), Kurt-Georg-Kiesinger-Allee 3, 53175 Bonn, North Rhine-Westphalia, Germany biomarker related drug response, pharmacogenetic information is included in the drug labels of drugs approved by medicines agencies to set the option, recommendation or demand to guide drug management by genetic testing [2]. In the European Union (EU), concrete companion tests are not specified in the drug labels. However, the new European Regulation (EU) 2017/746 on in vitro diagnostic medical devices states that the instructions for use of a companion diagnostic shall contain 'the International Non-proprietary Name (INN) of the corresponding medicinal product' [3]. The Regulation defines a companion diagnostic as a device that 'is essential for the safe and effective use of a corresponding medicinal product' [3]. Its application is intended to identify patients before and/or during treatment who most likely could benefit or likely have a higher risk of serious adverse drug reactions (ADRs) due to the use of the corresponding medicinal product [3].

The assessments by medicines agencies differ between countries and therefore so do the drugs approved for market entry [4]. The Pharmacogenomics Knowledge Base (PharmGKB) provides an overview of drugs approved by medicines agencies such as the US Food and Drug Administration (FDA), European Medicines Agency (EMA) and others, for which pharmacogenetic information is included into the respective drug labels [5].

Genetic tests that cover the biomarkers addressed in the drug labels or the Summary of Product Characteristics 
(SmPC) can be applied for guided drug therapy. However, the methodologies used continue to be developed or improved. Cost reductions for genetic testing material and services are increasing the amount of affordable genetic tests available for clinical diagnostics on the market. Therefore, the EMA does not provide information in the European public assessment reports (EPARs) on specific companion diagnostics to be used for predictive biomarker testing prior to a prescription of the respective drug [6]. On the basis of the new regulation (EU) $2017 / 746$ on in vitro diagnostic medical devices (date of application 26 May 2022) several changes apply that impact the regulatory framework and risk classification for companion diagnostics. Companion diagnostic tests such as genetic biomarker tests are classified as highrisk devices and require a conformity assessment by a notified body and a consultation procedure involving a medicinal products authority [3]. Furthermore, restrictions due to the new regulation affect the use of laboratory-developed assays and require a reorganization of genetic testing laboratories according to article $5.5[7,8]$. Molecular genetic tests placed on the market in the European Economic Area will have to be registered in the European database on medical devices (EUDAMED). EUDAMED will be in part accessible to the public [3, 9]. Genetic testing information can also be submitted voluntarily by testproviders worldwide to the Genetic Testing Registry (GTR) established by the National Institute of Health in the USA. The registry is a publicly accessible platform that can support the healthcare community with information on genetic tests offered commercially [10]. However, a comprehensive registry that encompasses the various types of available tests offered for clinical use is not yet available.

Here, we review a range of clinical genetic testing methods on the market classified as 'Molecular Genetics' by the National Center for Biotechnology Information (NCBI) Genetic Testing Registry that are used worldwide for clinical diagnostics. The focus is on clinical genetic and pharmacogenetic testing methods that were identified for biomarker analysis that could support guided treatment with approved drugs in the EU. We also elucidate the strengths, limitations and relative value of these methods for detecting biomarkers or molecular variants, respectively, and key challenges that are presented for selected technologies.

The results obtained for this review are based on data from the Genetic Testing Registry and PharmGKB and the authors therefore do not warrant comprehensiveness. Only test methodology of the GTR category 'Molecular Genetics' was evaluated for the drugs and biomarkers of interest without assessment on the suitability of the methods for each biomarker compared to other methods, for example, of further GTR categories such as 'Biochemical Genetics' and 'Cytogenetics' on the basis of regulatory clearances, clinical utility, and analytical and clinical validity. Registered tests were not evaluated with regard to Conformité Européenne (CE) marking according to directive 98/79/EC on in vitro diagnostic medical devices as such information was not provided in the GTR. The results in this review therefore are not appropriate for decision support in diagnostics or recommendations in clinical settings in Europe.

\section{Methods}

For this review, the PharmGKB drug label annotations providing information on the EMA-approved drugs with relevant pharmacogenetic drug label information were used. Thereby, the focus was on medication for which testing is required or recommended according to the Summary of Product Characteristics of the drug provided in the respective EPAR. Furthermore, a list of medications with drug labels that contain information regarding genetic, protein or chromosomal variants or phenotypes ['Actionable PGx' (i.e., Actionable Pharmacogenomics)] that affect dosage, metabolism, efficacy or toxicity of the respective drug is considered. This category also encompasses a contraindication of the medication in certain patient groups with specific variants, genotypes or phenotypes, which, however, do not result in recommendations or the requirement for genetic testing. The final updated lists of EU-approved medications were used to screen the database of the GTR for clinical genetic tests currently offered worldwide and could be of use for guided treatment. Here, only the GTR methodology section 'Molecular Genetics' was considered. Additionally, a screening was performed for molecular genetic testing methods targeting the respective biomarkers important for the identification of the specific genetic or chromosomal variants addressed in the EPARs for the drugs of interest. Methods were listed if they were identified for at least one medication or biomarker screened. Tests were excluded if the GTR screening results did not include the EPAR-specified biomarkers or if a lack of transparency on the applied methodology was detected. The lists were checked again for up-to-datedness in August 2020 with regard to the latest EPARs provided by the EMA and adjusted accordingly.

\section{Results}

An updated PharmGKB-derived list resulted in 58 considered drugs [Online Supplementary Material (ESM) 1] with information in the EPAR provided by the Summary of Product Characteristics specifying recommendations or the requirement for genetic testing in Europe prior to prescription. A screening of the GTR revealed that molecular genetic tests have been registered for about $38 \%$ of these drugs (Table 1). The tests cover the relevant biomarker or 
Table 1 Testing techniques identified by Genetic Testing Registry (GTR) screening of the methodology category 'Molecular Genetics'for drugs listed as 'Testing required' or 'Testing recommended' (EU) at PharmGKB

\begin{tabular}{|c|c|c|c|}
\hline Drug & Disease & Gene/Biomarker & Molecular genetics (GTR) \\
\hline Abacavir & $\begin{array}{l}\text { Human immunodeficiency virus } \\
\text { infection }\end{array}$ & $H L A-B * 5701$ & $\begin{array}{l}\text { CNV detection NGS + qPCR SNP } \\
\text { detection, allele-specific primer extension } \\
\text { (ASPE), sequence-specific PCR } \\
\text { (SSP-PCR), PCR with allele-specific } \\
\text { hybridization, sequence-specific } \\
\text { oligonucleotide probe (SSOP, SSO) }\end{array}$ \\
\hline Afatinib & Lung cancer & $\begin{array}{l}\text { Activating mutations of } \\
\text { EGFR-tyrosine kinase }\end{array}$ & PCR \\
\hline Arsenic trioxide & Acute promyelocytic leukaemia & $\mathrm{t}(15 ; 17)$ translocation & NGS/MPS \\
\hline Atazanavir & HIV infection & $\begin{array}{l}C Y P 2 C 19 * 2, * 3 \text { or other star alleles } \\
\text { related to decreased enzyme } \\
\text { function }\end{array}$ & Microarray \\
\hline Capecitabine & Colorectal neoplasms & $D P Y D$ & $\begin{array}{l}\text { CNV Detection NGS+qPCR SNP } \\
\text { Detection, microarray, SNP detection } \\
\text { (real-time PCR), competitive allele- } \\
\text { specific PCR (KASP) genotyping, SNP } \\
\text { detection (PCR/Single Nucleotide Primer } \\
\text { Extension) }\end{array}$ \\
\hline Carglumic acid & Hyperammonaemia & $N A G S$ & $\begin{array}{l}\text { NGS/ MPS, MLPA + bidirectional Sanger } \\
\text { sequence analysis + NGS/MPS, } \\
\text { bidirectional Sanger sequence analysis, } \\
\text { NGS/MPS + trinucleotide repeat by PCR } \\
\text { or Southern Blot, MLPA + NGS/MPS }\end{array}$ \\
\hline Cetuximab & Gastric cancer & $R A S$ & $\begin{array}{l}\text { Microarray, PCR with allele-specific } \\
\text { hybridization, bidirectional Sanger } \\
\text { sequence analysis, ASPE }\end{array}$ \\
\hline Cholic acid & $\begin{array}{l}\text { Inborn errors in primary bile acid } \\
\text { synthesis due to } 3 \beta \text {-hydroxy- } \Delta 5 \\
\text {-C } 27 \text {-steroid oxidoreductase deficiency } \\
\text { or } \Delta 4 \\
\text {-3-oxosteroid- } 5 \beta \text {-reductase deficiency in } \\
\text { infants, children and adolescents aged } \\
1 \text { month to } 18 \text { years and adults }\end{array}$ & $H S D 3 B 7, A K R 1 D 1$ & $\begin{array}{l}\text { NGS/MPS, NGS/MPS + bidirectional } \\
\text { Sanger sequence analysis }\end{array}$ \\
\hline Eliglustat & Gaucher's disease & $C Y P 2 D 6$ & $\begin{array}{l}\mathrm{CNV} \text { detection NGS + qPCR SNP } \\
\text { detection, microarray }\end{array}$ \\
\hline Erlotinib & Lung cancer & $E G F R$ & $\begin{array}{l}\text { NGS/MPS, PCR with allele-specific } \\
\text { hybridization, PCR }\end{array}$ \\
\hline Gefitinib & Lung cancer & $E G F R$ & $\begin{array}{l}\text { Bidirectional Sanger sequence analysis, } \\
\text { NGS/MPS, PCR with allele-specific } \\
\text { hybridization, PCR }\end{array}$ \\
\hline Ivacaftor & Mucoviscidosis & CFTR & Microarray \\
\hline $\begin{array}{l}\text { Lumacaftor/ } \\
\text { Ivacaftor }\end{array}$ & Cystic fibrosis & F508del mutation in the CFTR gene & Microarray \\
\hline Midostaurin & Acute myeloid leukaemia & FLT3 & PCR with allele-specific hybridization \\
\hline Nilotinib & Chronic myeloid leukaemia & $\begin{array}{l}\text { Philadelphia chromosome } \\
\text { (BCR-ABL1 gene fusion) }\end{array}$ & RT-PCR with gel analysis \\
\hline Olaparib & Ovarian Cancer & $B R C A$ & $\begin{array}{l}\text { Quantitative PCR + bidirectional Sanger } \\
\text { sequence analysis, NGS/MPS }\end{array}$ \\
\hline Panitumumab & Colon cancer & $K R A S, N R A S$ & $\begin{array}{l}\text { PCR with allele-specific hybridization, } \\
\text { bidirectional Sanger sequence analysis, } \\
\text { allele-specific primer extension (ASPE), } \\
\text { PCR }\end{array}$ \\
\hline
\end{tabular}


Table 1 (continued)

\begin{tabular}{|c|c|c|c|}
\hline Drug & Disease & Gene/Biomarker & Molecular genetics (GTR) \\
\hline Pembrolizumab & $\begin{array}{l}\text { Non-small-cell lung carcinoma } \\
\text { (NSCLC) } \\
\text { Head and neck squamous cell carcinoma } \\
\text { (HNSCC) } \\
\text { Urothelial carcinoma }\end{array}$ & PD-L1 & Fluorescence in situ hybridization (FISH) \\
\hline $\begin{array}{l}\text { Tezacaftor/ } \\
\text { Ivacaftor }\end{array}$ & Cystic fibrosis & CTFR F508del & Microarray \\
\hline Trastuzumab & Breast and gastric cancer & $E R B B 2$ (erythroblastic oncogene B) & $\begin{array}{l}\text { Microarray, bidirectional Sanger sequence } \\
\text { analysis }\end{array}$ \\
\hline $\begin{array}{c}\text { Trastuzumab } \\
\text { emtansin }\end{array}$ & Breast cancer & $E R B B 2$ & $\begin{array}{l}\text { Microarray, bidirectional Sanger sequence } \\
\text { analysis }\end{array}$ \\
\hline Vemurafenib & Melanoma & $B R A F$ & PCR with allele-specific hybridization \\
\hline
\end{tabular}

Drugs without entries were not listed. The overview does not privide a sufficient profile of suitable testing techniques for decision support in clinical diagnostics and therapy management in Europe as regulatory clearances, clinical utility, and analytical and clinical validity were not assessed in the evaluations for this review article

$A K R 1 D 1$ Aldo-keto reductase family 1, member D1, ASPE allele-specific primer extension, BRAF v-raf murine sarcoma viral oncogene homolog B1, CFTR Cystic Fibrosis Transmembrane Conductance Regulator, $C N V s$ copy number variations, $C Y P$ cytochrome P450, DPYD dihydropyrimidine dehydrogenase, EGFR epidermal growth factor receptor, $E R B B 2$ Erb-b2 receptor tyrosine kinase 2, FISH fluorescence in situ hybridization, FLT3 FMS-like tyrosine kinase-3, G6PD glucose-6-phosphate dehydrogenase, HLA-B*5701 human leukocyte antigen B*5701, $H S D 3 B 73 \beta$-hydroxy- $\triangle 5$-C27-steroid oxidoreductase, KASP competitive allele-specific polymerase chain reaction, KRAS Kirsten rat sarcoma viral oncogene homolog, MLPA Multiplex Ligation-dependent Probe Amplification, MPS massively parallel sequencing, NAGS N-acetylglutamate, $N G S$ next-generation sequencing, $N R A S$ neuroblastoma ras viral oncogene homolog, $P C R$ polymerase chain reaction, $P D-L 1$ programmed cell death ligand-1, $q P C R$ quantitative real-time PCR, $R T-P C R$ reverse transcriptase PCR

biomarkers such as chromosomal aberrations, single nucleotide polymorphysms (SNPs) and copy number variations $(\mathrm{CNVs})$ addressed in the corresponding EPAR of the respective approved drug.

Furthermore, for about $68.8 \%$ of the PharmGKB-derived list of 32 drugs (ESM 2) with pharmacogenetic information in the EPAR with reference to dosage, efficacy, metabolism or toxicity alterations due to addressed variants or phenotypes ('Actionable PGx'), molecular genetic tests covering the appropriate biomarker have been registered (Table 2). Identified combinations of testing techniques offered covering biomarkers of the 'Testing required'/'Testing recommended' list and the 'Actionable PGx' list were mainly sequencing-based methods such as Next-Generation (NGS)/ Massively Parallel Sequencing (MPS) with targeted PCRbased methods such as qPCR or MLPA.

A screening of the GTR by biomarkers relevant for the listed drugs resulted in a higher variety of applied tests, testing techniques and combinations of testing methods. Thereby PCR, hybridization and sequencing-based methods were identified in the GTR category 'Molecular Genetics'. The most frequently offered molecular genetic testing method for clinical assessment was NGS/MPS. Furthermore, frequently detected combinations of techniques for the 'Testing required' and 'Testing recommended' listing were NGS with Sanger Sequencing and MLPA with NGS or Bidirectional Sanger Sequencing or both. For the 'Actionable PGx' drug-gene pair list RT-qPCR combined with PCR with allele specific hybridization, PCR with Microarray, and MLPA with Bidirectional Sanger Sequencing were the most frequent combinations of applied techniques.

\subsection{PCR-Based Genetic Testing}

A highly important tool for diagnostic genetic testing is the polymerase chain reaction (PCR). The method is used to amplify DNA or RNA regions of interest, thereby increasing the copy number of the analysed sequences. Thus, it is particularly essential in targeted variant analyses [11].

In total, PCR-based tests were registered in the GTR for about $81 \%$ of the 58 drugs on the 'Testing recommended'/'Testing required' list and for about 84 $\%$ of the 32 drugs on the Actionable PGx list. Taking into account PCR based tests combined with other techniques, registrations were identified for $86 \%$ of the 'Testing required'/'Testing recommended' fraction and $94 \%$ of the 'Actionable PGx' fraction. For PCR-based genetic testing, most frequently RT-PCR or RT-qPCR (50\% and 56.3\%), MLPA (43.1 and $62.5 \%$ ), qPCR (29.3\% and 56.3\%) or PCR (36.2 and 62.5\%) were registered as an offered method for the biomarkers of interest (Table 3). Furthermore, in the 'Actionable PGx' fraction ASPE and competitive allelespecific PCR (KASP) were frequently offered methods for a targeted analysis of point mutations or SNPs. Most frequent combinations of PCR-based techniques for biomarker 
Table 2 Testing techniques identified by Genetic Testing Registry (GTR) screening of the methodology category 'Molecular Genetics' for drugs listed as 'Actionable PGx' (EU) at PharmGKB

\begin{tabular}{|c|c|c|c|}
\hline Drug & Disease & Gene/Biomarker & Molecular genetics (GTR) \\
\hline Amifampridine phosphate & $\begin{array}{l}\text { Lambert-Eaton myasthenic } \\
\text { syndrome }\end{array}$ & NAT2 & $\begin{array}{l}\text { CNV detection NGS + qPCR SNP } \\
\text { detection }\end{array}$ \\
\hline Aripiprazole & Schizophrenia & $C Y P 2 D 6$ & $\begin{array}{l}\text { RT-PCR, RT-qPCR, PCR with allele- } \\
\text { specific hybridization+SNP detection } \\
\text { (ASPE+Mass Spectrometry), CNV } \\
\text { detection NGS + qPCR SNP detection, } \\
\text { SNP detection }\end{array}$ \\
\hline Brexpiprazole & Schizophrenia & $C Y P 2 D 6$ & $\begin{array}{l}\text { CNV detection NGS + qPCR SNP } \\
\text { detection }\end{array}$ \\
\hline Brivaracetam & Epilepsy & CYP2C19 & $\begin{array}{l}\text { CNV detection NGS + qPCR SNP } \\
\text { detection, microarray }\end{array}$ \\
\hline Clopidogrel & $\begin{array}{l}\text { Secondary prevention of } \\
\text { atherothrombotic events, } \\
\text { prevention of atherothrombotic } \\
\text { and thromboembolic events in } \\
\text { atrial fibrillation }\end{array}$ & CYP2C19 & $\begin{array}{l}\text { NGS/ MPS, RT-PCR, MLPA, SNP } \\
\text { detection (real-time polymerase chain } \\
\text { reaction (PCR) + Single Nucleotide } \\
\text { Primer Extension), bidirectional } \\
\text { Sanger sequence analysis, solid-phase } \\
\text { electrochemical methodology, ASPE } \\
\text { + mass spectrometry, PCR with allele- } \\
\text { specific hybridization, RT-qPCR, } \\
\text { multiplex ligation-dependent probe } \\
\text { amplification (MLPA), quantitative } \\
\text { PCR (qPCR), KASP genotyping, , } \\
\text { quantitative PCR (qPCR), } \\
\text { RT-qPCR }\end{array}$ \\
\hline Darifenacin (hydrobromide) & $\begin{array}{l}\text { Urge incontinence and/or } \\
\text { increased urinary frequency } \\
\text { and urgency as may occur in } \\
\text { adult patients with overactive } \\
\text { bladder syndrome }\end{array}$ & CYP2D6 & $\begin{array}{l}\mathrm{CNV} \text { detection NGS + qPCR SNP } \\
\text { detection }\end{array}$ \\
\hline Dolutegravir & HIV infection & UGT1A1 & $\begin{array}{l}\text { CNV detection NGS + qPCR SNP } \\
\text { detection }\end{array}$ \\
\hline Duloxetine & $\begin{array}{l}\text { Treatment of major depressive } \\
\text { disorder } \\
\text { Treatment of diabetic peripheral } \\
\text { neuropathic pain } \\
\text { Treatment of generalised anxiety } \\
\text { disorder }\end{array}$ & $C Y P 2 D 6$ & SNP detection, RT-qPCR \\
\hline Efavirenz & HIV infection & $C Y P 2 B 6$ & $\begin{array}{l}\text { MLPA, NGS/ MPS, MLPA + } \\
\text { bidirectional Sanger sequence analysis, } \\
\text { bidirectional Sanger sequence analysis, } \\
\text { CNV detection NGS + qPCR + } \\
\text { SNP detection (NGS), NGS/MPS + } \\
\text { bidirectional Sanger sequence analysis, } \\
\text { SNP detection (real-time PCR, } \\
\text { microarray analysis), qPCR, } \\
\text { RT-qPCR, KASP genotyping }\end{array}$ \\
\hline $\begin{array}{l}\text { Efavirenz/emtricitabine/ } \\
\text { tenofovir disoproxil }\end{array}$ & HIV infection & $C Y P 2 B 6$ & $\begin{array}{l}\text { MLPA, NGS/ MPS, MLPA + } \\
\text { bidirectional Sanger sequence } \\
\text { analysis, bidirectional Sanger sequence } \\
\text { analysis, CNV } \\
\text { detection NGS + qPCR SNP } \\
\text { detection, NGS/MPS + } \\
\text { bidirectional Sanger sequence analysis, } \\
\text { SNP detection (real-time PCR, } \\
\text { microarray analysis), qPCR, RT-qPCR, } \\
\text { KASP genotyping }\end{array}$ \\
\hline
\end{tabular}


Table 2 (continued)

\begin{tabular}{|c|c|c|c|}
\hline Drug & Disease & Gene/Biomarker & Molecular genetics (GTR) \\
\hline $\begin{array}{c}\text { Ethinyl estradiol/ } \\
\text { norelgestromin }\end{array}$ & Female contraception & $\begin{array}{l}\text { Predisposition for venous } \\
\text { thromboembolism (including } \\
\text { F5), antithrombin-III deficiency } \\
\text { (SERPINC1), protein } \mathrm{C} \\
\text { deficiency }(P R O C) \text { and protein } \mathrm{S} \\
\text { deficiency }(P R O S))\end{array}$ & Microarray \\
\hline Fesoterodine & $\begin{array}{l}\text { Treatment of the symptoms that } \\
\text { may occur with overactive } \\
\text { bladder syndrome }\end{array}$ & CYP2D6 (poor metabolism) & CNV NGS + qPCR SNP detection \\
\hline Gefitinib & $\begin{array}{l}\text { Advanced or metastatic } \\
\text { non-small-cell lung cancer }\end{array}$ & $C Y P 2 D 6$ (poor metabolism) & $\begin{array}{l}\text { CNV NGS + qPCR SNP detection, SNP } \\
\text { detection, RT-qPCR }\end{array}$ \\
\hline Glibenclamide & Neonatal diabetes mellitus & $G 6 P D$ (deficiency) & SNP detection \\
\hline Glimepiride & Type 2 diabetes mellitus & $G 6 P D$ (deficiency) & SNP detection, microarray \\
\hline Irinotecan & $\begin{array}{l}\text { Metastatic adenocarcinoma of the } \\
\text { pancreas }\end{array}$ & $\begin{array}{l}\text { Homozygozity for } U G T 1 A 1 * 28 \\
\text { allele }\end{array}$ & $\begin{array}{l}\text { PCR electrophoresis, capillary gel, PCR, } \\
\text { fragment analysis, } \\
\text { bidirectional Sanger sequence analysis, } \\
\text { PCR with allele-specific hybridization, } \\
\text { PCR capillary gel electrophoresis }\end{array}$ \\
\hline Lapatinib & $\begin{array}{l}\text { Breast cancer, in which tumours } \\
\text { overexpress HER2 (ErbB2) }\end{array}$ & $\begin{array}{l}H L A-D Q A 1 * 02: 01 \text { and } H L A- \\
\quad D R B 1 * 07: 01\end{array}$ & Microarray \\
\hline Lesinurad & Hyperuricaemia in gout patients & $C Y P 2 C 9$ (poor metabolism) & Microarray, ASPE + mass Spectrometry \\
\hline Mercaptopurine & $\begin{array}{l}\text { Acute lymphoblastic leukaemia } \\
\text { (ALL) }\end{array}$ & TPMT, NUDT15 & $\begin{array}{l}\text { RT-qPCR, RT-PCR with gel analysis, } \\
\text { Microarray, CNV detection NGS } \\
\text { quantitative PCR (qPCR) SNP } \\
\text { detection, PCR }\end{array}$ \\
\hline Pazopanib & Advanced renal cell carcinoma & $H L A-B$ & $\begin{array}{l}\text { CNV detection NGS + qPCR SNP } \\
\text { detection }\end{array}$ \\
\hline Rasburicase & Acute hyperuricaemia & $G 6 P D$ & Microarray (D,T), NGS/MPS \\
\hline Vortioxetine & Major depressive episodes & CYP2D6 & $\begin{array}{l}\text { CNV Detection NGS + qPCR SNP } \\
\text { Detection }\end{array}$ \\
\hline
\end{tabular}

The overview does not privide a sufficient profile of suitable testing techniques for decision support in clinical diagnostics and therapy management in Europe as regulatory clearances, clinical utility, and analytical and clinical validity were not assessed in the evaluations for this review article

$A S P E$ allele-specific primer extension, $C N V s$ copy number variations, $C Y P$ cytochrome P450, $F 5$ factor 5, G6PD glucose-6-phosphate dehydrogenase, $H L A-B * 5701$ human leukocyte antigen $\mathrm{B} * 5701, H L A-D Q A 1$ major histocompatibility complex, class II, DQ alpha 1, HSD3B7 $3 \beta$-hydroxy- $\triangle 5$-C27-steroid oxidoreductase, KASP competitive allele specific PCR, MLPA Multiplex Ligation-dependent Probe Amplification, $M P S$ massively parallel sequencing, NAT2 N-acetyltransferase 2, NGS next-generation sequencing, NUDT15 nudix hydrolase $15, P C R$ polymerase chain reaction, $P R O C$ Protein $\mathrm{C}, P R O S$ Protein $\mathrm{S}, q P C R$ quantitative real-time PCR, RT-PCR reverse transcriptase PCR, SERPINC1 serpin family C member 1, SNPs single nucleotide polymorphysms, TPMT thiopurine S-methyltransferase, UGT1A1 uridine diphosphate glucuronosyltransferase $1 \mathrm{~A} 1$

analysis were PCR with NGS, PCR with Microarray, and MLPA with sequencing-based methods.

PCR is often used to amplify nucleic acid sequences to be analysed for probable mutations by other methods, for example sequencing [12]. However, for genotyping PCR can also directly be used for detection and is a cost-effective method [13]. Furthermore, techniques such as real-time PCR (qPCR) [14] and real-time quantitative RT-PCR (RT-qPCR) [15], the amplification refractory mutation system (ARMS) [16] or multiplex ligation-dependent probe amplification (MLPA) [17] are also used as primary mutation or variant-detection systems. Nevertheless, they can only detect mutations that have been previously characterized and thus are suitable for a targeted analysis [18]. Further advantages and limitations of PCR-based methods are listed in Table 4.

In leukaemia RT-qPCR, which allows a quantification of RNA expression, offers clinically relevant information regarding drug response and treatment stratification. However, a limited accuracy in many diagnostic applications and lack of standardization between laboratories has been reported [19]. In addition, for ALK testing it was assumed that NGS will become the first tier method [20].

Real-time quantitative PCR is used for targeted genetic analysis such as the determination of SNP genotype and sequence copy number in molecular diagnostics. A diagnostically relevant example for a real-time PCR approach 
Table 3 PCR-based methods registered in the Genetic Testing Registry (GTR) for biomarker analysis regarding drug response

\begin{tabular}{lcr}
\hline PCR-based methods 'Molecular genetics' & $\begin{array}{l}\text { Percentage of drugs ('Testing recommended' and 'Testing } \\
\text { required') (\%) }\end{array}$ & $\begin{array}{l}\text { Percentage of drugs } \\
\text { ('Actionable PGx') } \\
(\%)\end{array}$ \\
\hline ARMS & 3.4 & - \\
ASPE & 19.0 & 53.1 \\
KASP & 5.2 & 43.8 \\
MLPA & $\mathbf{4 3 . 1}$ & $\mathbf{6 2 . 5}$ \\
PCR & $\mathbf{3 6 . 2}$ & $\mathbf{6 2 . 5}$ \\
QF PCR & - & 6.3 \\
qPCR & $\mathbf{2 9 . 3}$ & $\mathbf{5 6 . 3}$ \\
RFLP & 12.1 & 50.0 \\
RT-PCR/ RT-qPCR & $\mathbf{5 0 . 0}$ & $\mathbf{5 6 . 3}$
\end{tabular}

Most frequenty applied techniques in both listings ('Testing recommended'/'Testing required' and 'Actionable PGx') are marked in bold $A R M S$ amplification refractory mutation system, ASPE allele-specific primer extension, KASP competitive allele-specific PCR, MLPA multiplex ligation-dependent probe amplification, $P C R$ polymerase chain reaction, $Q F-P C R$ quantitative fluorescent PCR, $q P C R$ quantitative real-time PCR, $R T-P C R$ reverse transcriptase PCR, RFLP Restriction Fragment Length Polymorphism Analysis

utilising fluorescent probes is the TaqMan ${ }^{\circledR}$ assay (Thermo Fisher Scientific, Waltham, MA, USA). It has been used for the identification of several clinically important mutations [21].

After amplification of the region of interest by realtime polymerase chain reaction, high-resolution melting analysis can be performed for gene scanning and genotyping in a thermal cycler. It is a simple, sensitive and specific technique and a suitable option for laboratories with resource constraints. Deviations in the melting profiles compared to wild type homozygotes also indicate heterozygous variants [22]. However, melting temperatures (Tm) of some homozygous single-base variants, insertions and deletions can be similar or even identical and thus cannot be distinguished. Therefore, simple amplicon melting is not always sufficient to accurately genotype certain loci [23].

PCR-RFLP can be routinely applied for SNP genotyping, detection of point mutations and to discriminate homozygous and heterozygous samples related to the target sequence [24]. This PCR-based technique was applied to screen for, for example, Kirsten rat sarcoma viral oncogene homolog (K-ras) and epidermal growth factor receptor (EGFR) mutations in cancer diagnostics [25, 26]. It also provides a cost-effective possibility for pharmacogenetic screening of SNPs in order to optimise drug therapy, especially in developing countries [27, 28]. In clinical routine, a combination of PCR-RFLP with other PCR-based methods for targeted analysis such as TaqMan ${ }^{\circledR}$ PCR and high-resolution melting analysis can improve the accuracy and reduce the risk of false-negative or false-positive test results. Thereby, the limitations of a single method leading to a lack of sensitivity or specificity can be overcome and improve the selection of individualized therapies
[29]. Also, the allele-specific primer extension approach is widely used for genotyping of single-nucleotide polymorphisms (SNPs). However, methods for analysis include many different approaches such as electrophoresis, fluorescence resonance energy transfer, pyrosequencing, microarrays and matrix-assisted laser desorption/ionization-time of flight (MALDI) mass spectrometry [30, 31]. MALDI mass spectrometry is a relatively fast high-throughput method for SNP detection that provides a high sensitivity and specificity. The process does not require labeling the primers as it measures the molecular weight differences after primer extension [32, 33]. Compared to pyrosequencing and other costly sequencing methods, it can provide a cost-efficient option for accurate targeted genotyping in guided drug therapy [34-36]. MLPA is a semiquantitative PCR-based method that is suitable for the assessment of genetic loci for detection of CNVs in several types of disorders [37]. Furthermore, it can be used to detect mosaic mutations and methylation status. It also provides the possibility to detect single nucleotide differences. MLPA can be applied, for example, on DNA samples extracted from frozen or paraffin-embedded formaldehyde-fixed breast cancer tissues for the detection of ERBB2 (Her2/neu) amplification [37]. This technique can be also applied to confirm test results on structural anomalies obtained by FISH or comparative genomic hybridization $(\mathrm{CGH})$ [38]. The application of MLPA for CNV analysis is more sensitive and cheaper than the utilization of DNA arrays. A further advantage over DNA arrays is that sample preparation time for MLPA is lower [38, 39]. However, balanced genomic rearrangements, such as translocations or inversions, cannot be identified by MLPA [38]. 
Table 4 Advantages and limitations of PCR-based methods identified by Genetic Testing Registry (GTR) screening for relevant biomarkers

\begin{tabular}{ll}
\hline PCR-based method & Advantages \\
\hline $\begin{array}{l}\text { ARMS (amplification } \\
\text { refractory mutation } \\
\text { system, allele- }\end{array}$ & $\begin{array}{l}\text { Simple technique, quick, allele specific } \\
\text { specific PCR) } \\
\text { deletions and insertions }\end{array}$ \\
& $\begin{array}{c}\text { Determination of haplotypes in clinical } \\
\text { diagnostics possible } \\
\text { Can also be multiplexed }\end{array}$ \\
& Applicable also in resource-constrained \\
& circumstances due to low costs \\
ASPE & Applicable for high-throughput analysis
\end{tabular}

KASP

MLPA

PCR-RFLP

QF-PCR

qPCR

RT-PCR/q-RT-PCR
Identification of SNPs or InDels,

cost-

effective, can be multiplexed, applicable also in resource-constrained circumstances due to low costs

Fast, and relatively simple technique, low costs detection of CNVs and mosaic mutations

Simple and rapid technique for SNP genotyping, detection of point mutations and discrimination of homozygous and heterozygous samples

Accurate and cost-effective method applied for detection of aneuploidy, detection of mosaicism

Closed-tube technique, limits danger of contamination

High sensitivity and specificity

Multiplexing of reactions and fast analysis possible

Gene expression analysis

\begin{tabular}{lc} 
Limitations & Reference \\
\hline Inefficient priming can occur & Frayling et al. \\
& [18], Yang et al. \\
[68], Little [69], \\
Markou et.al [16]
\end{tabular}

Further methods for analysis needed such as electrophoresise or matrix-assisted laser

Breyer et al. [30] desorption/ionization-time of flight (MALDI) mass spectrometry

Multiplexing limited to single bi-allelic SNP per reaction

Suo et al. [70], Shitaye [71], He et al. [72]

Sensitive to DNA quality and quantity

Ligation failure due to point mutations in probe binding site and therefore erroneously indication of deletions possible

No detection of balanced genomic rearrangements

Limited availability of suitable restriction enzymes

Katsanis [38], Frayling et al. [18]

No detection of structural abnormalities

Mann and Ogilvie [73], Konjhodzic et al. [74]

Limited combinations of fluorescent dyes for Frayling et al. [18] multiplexing

Ota et al. [24]

Sensitive to RNA quality

Murphy and

Bustin [19]

Most frequenty applied techniques in both listings ('Testing recommended'/'Testing required' and 'Actionable PGx') are shaded in bold $A R M S$ amplification refractory mutation system, ASPE allele-specific primer extension, KASP competitive allele-specific PCR, MLPA multiplex ligation-dependent probe amplification, $P C R$ polymerase chain reaction, $Q F-P C R$ quantitative fluorescent PCR, $q P C R$ quantitative real-time PCR, RT-PCR reverse transcriptase PCR, RFLP Restriction Fragment Length Polymorphism Analysis

\subsection{Hybridization-Based Techniques}

Developments in the field of genetic-testing techniques made it possible to investigate complex genetic abnormalities using targeted gene panels and even information on the entire exome or genome. Hybridization-based techniques such as oligonucleotide arrays are also used for such highthroughput purposes [39].

The analysis of GTR-registered tests screened by biomarker detected hybridization-based tests for $65.5 \%$ of drugs for which genetic testing is recommended or required and for about $78.1 \%$ with information on actionable pharmacogenomics according to the corresponding EPAR.
Registrations of hybridization-based tests including combinations of such tests with other techniques were identified for $74.1 \%$ of the 'Testing required' $/$ 'Testing recommended' fraction and $87.5 \%$ of the 'Actionable PGx' fraction. For hybridization-based testing, most frequently techniques such as microarray analysis and PCR with allele-specific hybridization are registered as an offered method for the biomarkers of interest. Furthermore, techniques such as FISH and CGH that occur mainly in the GTR test category 'Cytogenetics' were also registered as 'Molecular Genetics' for the biomarkers analysed. Here, FISH was identified as a registered molecular genetic technique for $20.7 \%$ of drugs in the 'Testing required' and 'Testing recommended' 
section (Table 5). In the 'Actionable PGx' section, for $21.9 \%$ of the respective drug-biomarker pairs $\mathrm{CGH}$ is registered as a molecular genetic technique for predictive analysis of drug response. Most frequent combinations of hybridizationbased techniques with other methods for biomarker analysis were microarray with NGS ('Testing required'/'Testing recommended') and microarray with PCR or a combination of RT-PCR/RT-qPCR and PCR with allele specific hybridization ('Actionable PGx').

PCR with allele-specific hybridization or allele-specific oligonucleotide (ASO) hybridization is a simple, efficient and cost-effective method for the analysis of several genetic variants in a large number of samples. Thus, it can be used for large-scale genotyping of SNPs and provides results faster than RFLP-PCR. The PCR products of the region of interest can either be dot-blotted or integrate a quantifiable label (e.g., biotin or fluorescent labels). Polymorphisms are detected due to hybridization with wild type and mutant variant specific ASO probes via a dot blot assay or a reverse-hybridisation assay [40]. ASOs immobilised onto solid surfaces can be used for Microarrays (e.g., Affymetrix Genechip ${ }^{\circledR}$ Mapping 10K Array). However, for accurate hybridization in a large-scale genotyping approach conditions for different mutations can vary. In Microarrays, where a high number of different mutation sites are analysed simultaneously, this can be overcome by using a large set of ASOs for each target region [21]. Developments in this 'chip' technology permit a parallel analysis of various genome regions and genotyping of numerous different genes at the same time [41]. Microarrays are applied as SNP panels either phenotype-specific or genome-wide or to identify structural anomalies by array CGH. CGHs, just like fluorescence in situ hybridization, are hybridization-based methods that are also used as cytogenetic methods in cancer diagnostics to identify genomic abnormalities [38].

\subsection{Sequencing-Based Techniques}

The results of the GTR screening reflect the increased focus and shift of services and applications towards NGS. For $96.6 \%$ of drugs for which genetic testing is recommended or required and for about $93.8 \%$ with information on actionable pharmacogenomics according to the corresponding EPAR, GTR-registered sequencing-based tests were detected in a screening by biomarker of interest. Registrations of sequencing-based tests including combinations of such tests with other techniques were even identified for $100 \%$ of the listed drug-gene pairs of the 'Actionable PGx' fraction. Most frequently, NGS/MPS (Table 6) is registered as an offered method for the biomarkers of interest. Frequent combinations of sequencing-based techniques and sequencing-based techniques with other methods identified were for example NGS with Bidirectional Sanger Sequencing, NGS with MLPA, Bidirectional Sanger Sequencing with MLPA or NGS with Bidirectional Sanger Sequencing and MLPA. NGS with Bidirectional Sanger sequencing was identified as the most frequent combination in the 'Testing required'/'Testing recommended' section (34.5\%) and Bidirectional Sanger Sequencing with MLPA as the most frequently offered combination for the 'Actionable PGx' section.

Compared to conventional Sanger sequencing, Pyrosequencing has a superior detection limit for short reads and is an easier methodology with fewer steps involved. It has been used for genetic testing, methylation analysis, re-evaluations of equivocal Sanger sequencing results or confirmation of NGS results. The read length limit of this technique is about 400 bases [42]. However, Sanger sequencing, the current gold standard for genetic testing and validating DNA sequences obtained by other sequencing methods, is continuously replaced by NGS. NGS can be applied for targeted gene panels, whole exome sequencing and whole genome sequencing, and provides a resolution to single-base precision while permitting large amounts of DNA fragments to be sequenced simultaneously and independently [43-46]. It

Table 5 Hybridization-based methods registered in the Genetic Testing Registry (GTR) for biomarker analysis

\begin{tabular}{lcc}
\hline Hybridization-based methods 'Molecular Genetics' & $\begin{array}{l}\text { Percentage of drugs ('Testing recommended' and } \\
\text { 'Testing required') (\%) }\end{array}$ & $\begin{array}{l}\text { Percentage of drugs } \\
\text { ('Actionable PGx') } \\
(\%)\end{array}$ \\
\hline Reverse dot blot hybridization & 1.7 & - \\
PCR with allele specific hybridization & $\mathbf{4 1 . 4}$ & $\mathbf{3 7 . 5}$ \\
Microarray & $\mathbf{3 6 . 2 1}$ & $\mathbf{6 8 . 8}$ \\
CGH & 8.6 & 21.9 \\
FISH & 20.7 & 3.1 \\
\hline
\end{tabular}

Most frequenty applied techniques for both listings ('Testing recommended'/'Testing required' and 'Actionable PGx') are shaeded in bold FISH fluorescence in situ hybridization, $C G H$ comparative genomic hybridization 
is also used in new diagnostic concepts such as liquid biopsy assays $[47,48]$, and was shown to be suitable in routine clinical practice for this application $[49,50]$. Furthermore, it is used to test for emerging biomarkers in cancer treatment such as Microsatellite instability and Tumor mutation burden, which are predictive for immunotherapy response $[51,52]$. Therefore the outlook for NGS becoming a new standard for genetic or companion diagnostics, respectively, is intensifying, although several methods can be used for genetic testing of the same diagnostic target of interest [53]. However, Sanger sequencing is still applied as a first-line approach in genetic diagnostics of some specific conditions [46]. Compared to the Sanger platform, next-generation platforms perform shorter reads and deliver lower quality, which makes appropriate bioinformatic tools indispensable for the assistance of short-read mapping to reference sequences or de novo assembly [54]. Therefore, despite the decreasing costs, high expenditures related to NGS and a lack of skills in the application of bioinformatics tools and algorithms for the interpretation of test results are still a major limitation issue in the utilization of this technique [53].

There are several sequencing platforms that are applied and offered for genetic analysis. Currently, due to the availability of a wide variety of products on the market, which can be selected according to requirements for different medical or scientific applications, a high sequencing precision can be obtained [46, 55]. A wide variety of Illumina (San Diego, CA, USA) sequencing platforms such as HiSeq, MiSeq, NovaSeq 6000 and NextSeq 550/500 sequencer are indicated for genetic tests applying sequencing-based methods registered at GTR. However, the HiSeq plattforms currently are not provided [56] by Illumina and full support by the manufacturer will expire in about 3-4 years with HiSeq X Five and Ten Systems [57] and HiSeq 4000 [58] support expiring by the end of March 2024 at the latest. Further current platforms, for example, are Life Technologies (now Thermo Fisher Scientific, Waltham, MA, USA), Ion Torrent

Table 6 Sequencing based methods registered in the Genetic Testing Registry (GTR) for biomarker analysis regarding drug response

\begin{tabular}{lll}
\hline $\begin{array}{l}\text { Sequencing- } \\
\text { based techniques } \\
\text { 'Molecular Genetics' }\end{array}$ & $\begin{array}{l}\text { Drug-gene pairs ('Testing } \\
\text { recommended' and 'Testing } \\
\text { required') }\end{array}$ & $\begin{array}{l}\text { Drug-gene pairs } \\
\text { ('Actionable } \\
\text { PGx') }\end{array}$ \\
\hline $\begin{array}{lll}\text { Sanger sequencing } \\
\begin{array}{l}\text { Next-generation } \\
\text { sequencing/ } \\
\text { massively parallel }\end{array}\end{array}$ & $\mathbf{5 6 . 9 \%}$ & $\mathbf{7 5 . 0 \%}$ \\
$\begin{array}{l}\text { sequencing } \\
\text { Pyrosequencing }\end{array}$ & $3.4 \%$ & $\mathbf{9 6 . 9 \%}$ \\
\hline
\end{tabular}

Most frequenty applied techniques for both listings ('Testing recommended'/'Testing required' and 'Actionable PGx') are shaded in bold and the third-generation (long-read) sequencing Pacific Bioscience's SMRT (Menlo Park, CA, USA) and Oxford Nanopore Technologies' (Oxford Science Park, Oxford, UK) plattforms (Table7).

\section{Discussion}

On the basis of pharmacogenetic and pharmacogenomic information in the drug labels, molecular diagnostics through predictive biomarker analysis using pharmacogenetic and pharmacogenomic tests can support treatment prognosis in particular patient subgroups and direct drug management. Thereby, a targeted approach prevails as the basis for genetic testing in the clinical setting [38].

PCR-based methods such as MLPA and qPCR/RTqPCR and hybridization-based methods such as Microarrays are frequently applied and offered as laboratory testing services worldwide according to the GTR screening results obtained for this review. However, NGS was offered for analysis of most of the biomarkers relevant for EUauthorized drugs for which testing is optional ('Actionable PGx'), recommended or required according to the respective EPAR. Thus, the gain in importance of NGS for genetic diagnostics becomes apparent with the identified main emphasis on this technique for clinical use in laboratory services worldwide as reflected by the GTR data in this review. Rapid developments in NGS regarding bioinformatics to overcome obstacles in the use of this method certainly contribute to this trend. However, although genomic data analysis provides important clinical information, it is not a holistic approach. In the application of liquid biopsy, for example, the analysis of circulating tumor DNA is essential; however, other liquid biopsy biomarkers such as circulating tumor cells [59], exosomes [60], metabolites, proteins and circulating RNAs can be applied as well [61]. Therefore, other testing methodologies like proteomic testing will remain relevant [39]. It is therefore essential to assess how different assays perform, and where and in which combination they could be used for an accurate result [4]. The most frequent combination of methods registered for biomarkers for which testing is recommended or required prior to prescription of the respective drug was NGS with bidirectional Sanger sequencing.

Sanger sequencing has been an accurate and reliable approach, and was therefore used as a gold standard for genetic testing in the past years [43, 62]. Nonetheless, limitations such as high costs and time expenditure led to a shift in the application to NGS as a faster and less expensive sequencing technique able to sequence high numbers of genes at the same time [62]. Still, Sanger sequencing is used as a confirmatory method for NGS to achieve a higher 
Table 7 Overview of selected sequencing applications

\begin{tabular}{|c|c|c|c|c|}
\hline Sequencing technique & Mechanism [46] & Maximal reads length & Advantages & Disadvantages \\
\hline Illumina Sequencing & $\begin{array}{l}\text { Sequencing by synthesis } \\
\text { (cyclic reversible } \\
\text { termination) }\end{array}$ & $2 \times 150-300$ bp [56] & $\begin{array}{l}\text { High throughput sequencing } \\
\text { [75] }\end{array}$ & Short read length [46] \\
\hline $\begin{array}{l}\text { Ion Torrent }{ }^{\mathrm{TM}} \text { semiconductor } \\
\text { sequencing }\end{array}$ & $\begin{array}{l}\text { Sequencing by synthesis } \\
\text { (single-nucleotide addition) }\end{array}$ & 200-600 bp [76] & $\begin{array}{l}\text { Fast turnaround time, } \\
\text { flexibility [77] }\end{array}$ & $\begin{array}{l}\text { Accuracy and output } \\
\text { affected by read } \\
\text { length }[78,79]\end{array}$ \\
\hline $\begin{array}{l}\text { SMRT from Pacific } \\
\text { Bioscience }\end{array}$ & $\begin{array}{l}\text { Single-molecule real-time } \\
\text { long read sequencing }\end{array}$ & up to $25 \mathrm{~kb}$ [80] & Long read length [80] & High error rate [81] \\
\hline $\begin{array}{l}\text { Oxford Nanopore's } \\
\text { sequencing }\end{array}$ & $\begin{array}{l}\text { Single-molecule real-time } \\
\text { long read sequencing }\end{array}$ & $>4 \mathrm{Mbp}[82]$ & Ultra-long reads [82] & High error rate [83] \\
\hline
\end{tabular}

$b p$ base pairs, $k b p$ kilo base pairs, $M b p$ mega base pairs

sensitivity and for quality-assurance measures. However, the necessity of such a confirmation is controversial as it can be inefficient [63]. Nevertheless, medium and large deletions or insertions cannot be detected accurately by sequencing alone without confirmatory techniques such as MLPA or qPCR [1].

According to GTR data, genetic testing by MLPA is often also offered in combination with sequencing-based methods such as NGS, Sanger sequencing or both for deletion and duplication analysis in clinical diagnostics, and can be applied for guided therapy. Deletions are indicated if MLPA probes cannot hybridize to their binding site due to a point mutation or polymorphism in the respective sequence, therefore additional techniques are necessary for the confirmation of MLPA results. Furthermore, the orientation of a duplicated sequence and an exact localization cannot be identified by MLPA only [64].

Limitations are indicated for every technique currently offered on the market worldwide (Table 3). For an accurate and reliable detection of genetic and pharmacogenomic biomarkers, the status should therefore be analysed by several suitable and complementary methods.

This review provides an overview of the molecular genetic testing methods offered worldwide for clinical applications that could be considered for companion diagnostic tests for several EU-approved drugs as they cover biomarkers addressed in the relevant EPARs. Nevetheless, the evaluation was restricted to only molecular genetic techniques, which are not always optimal for several biomarkers such as PD-L1 or HER2 (ERBB2). For these biomarkers, FISH or Microarray and Bi-directional Sanger-sequence analysis was identified as the registered method in the GTR in the screening by drug; however, more suitable tests based on clinical studies such as immunohistochemistry were mentioned in the associated EPARs, for example for pembrolizumab (PD-L1 IHC 22C3 pharmDxTM Kit) [65] and trastuzumab (HER2 analysis by ICH and FISH) [66], respectively.
For an in vitro diagnostic (IVD) such as a companion diagnostic, assessment and documentation of the scientific validity and analytical and clinical performance is required. Furthermore, for the EU market, a demonstration of conformity with the IVD regulation is obligatory and has to be indicated by CE marking [3]. However, information on in vitro diagnostic $\mathrm{CE}$ marking according to $\mathrm{EU}$ regulation was not identified in the screening of the GTR. Therefore, a major limitation is that this overview relies on data of the GTR, which is not a comprehensive registry as it is established on a voluntary basis, and information on regulatory clearances and analytical and clinical validity of the registered tests is rarely included in the associated sections of the GTR by test providers. Therefore, it cannot deliver a sufficient profile of tests and testing techniques across the genetic testing landscape in clinical settings for decision support in clinical diagnostics and therapy management in Europe. A registry based on a mandatory registration to enhance transparency on clinical genetic tests and test validity internationally was recommended more than 10 years ago; however it has not been established yet [67].

\section{Conclusions}

For an accurate and reliable determination of pharmacogenetic and pharmacogenomic biomarkers of relevance for personalized drug therapy, sequencing-based methods are useful techniques that are gaining importance for clinical practice. NGS in particular is an increasingly accessible and affordable application for routine clinical diagnostics. Molecular genetic tests are offered for clinically relevant genomic regions for which testing is currently optional, required or recommended to guide drug therapy. Also, most biomarkers relevant for prescriptions of approved drugs in Europe are covered by worldwide-offered NGS 
applications. However, there are still obstacles to translating the test results into appropriate treatment recommendations. Furthermore, genetic testing is not a holistic approach. Advancements in other clinically relevant fields such as proteomics may contribute to further important biomarkers and diagnostic testing methodologies. The speed in such developments presents a challenge to future standardization and regulation in the use of companion diagnostics.

Supplementary Information The online version contains supplementary material available at https://doi.org/10.1007/s40291-021-00567-X.

Acknowledgements The authors would like to express their gratitude to Dr. Camilla Lambertz, PD Dr. Kathrin Lange, Prof. Dr. Wolfgang Lauer and scientists of the regulatory departments of the Federal Institute for Drugs and Medical Devices for critical reviewing of and advice for the manuscript.

Funding Open Access funding enabled and organized by Projekt DEAL.

\section{Declarations}

Funding The research for this review was supported by the Federal Ministry of Health in Germany (grant number: ZMVI1-2519FSB404) within the framework of the project Regulatory Research on Companion Diagnostics (RegCDx).

Conflict of Interest The authors declare that research for this review article was performed without commercial or financial interests.

Ethics Approval Not applicable.

Consent to Participate Not applicable.

Consent for Pusadblication Not applicable.

Availability of Data and Materials The datasets used and/or analysed during the current study are available from the corresponding author on reasonable request.

Code Availability Not applicable.

Author Contributions The registry and database research for the article was planned and carried out by TH. The first draft was written by TH with support of CS and MS. CS and MS revised the manuscript. All authors approved the final version.

Open Access This article is licensed under a Creative Commons Attribution-NonCommercial 4.0 International License, which permits any non-commercial use, sharing, adaptation, distribution and reproduction in any medium or format, as long as you give appropriate credit to the original author(s) and the source, provide a link to the Creative Commons licence, and indicate if changes were made. The images or other third party material in this article are included in the article's Creative Commons licence, unless indicated otherwise in a credit line to the material. If material is not included in the article's Creative Commons licence and your intended use is not permitted by statutory regulation or exceeds the permitted use, you will need to obtain permission directly from the copyright holder. To view a copy of this licence, visit http://creativecommons.org/licenses/by-nc/4.0/.

\section{References}

1. Lohmann K, Klein C. Next generation sequencing and the future of genetic diagnosis. Neurotherapeutics. 2014;11(4):699-707. https://doi.org/10.1007/s13311-014-0288-8 (published Online First: 2014/07/24).

2. Shimazawa R, Ikeda M. Differences in pharmacogenomic biomarker information in package inserts from the United States, the United Kingdom and Japan. J Clin Pharm Ther. 2013;38(6):46875. https://doi.org/10.1111/jcpt.12089 (published Online First: 2013/07/31)

3. EUR-Lex. Regulation (EU) 2017/746 of the European Parliament and of the COUNCIL: EUR-Lex; 2020. https://eur-lex.europa.eu/ legal-content/EN/TXT/?uri=CELEX:32017R0746. Accessed 04 Mar 2021

4. EMA. Guideline on the use of pharmacogenetic methodologies in the pharmacokinetic evaluation of medicinal products. In: (CHMP) CfMPfHU, editor. EMA; 2011.

5. PharmGKB. Drug Label Annotations: PharmGKB; 2020. https:// www.pharmgkb.org/labelAnnotations. Accessed 25 Aug 2020.

6. (CHMP) CfMPfHU. Concept paper on predictive biomarker-based assay development in the context of drug development and lifecycle; 2017.

7. Bank PCD, Jacobs LHJ, van den Berg SAA, et al. The end of the laboratory developed test as we know it? Recommendations from a national multidisciplinary taskforce of laboratory specialists on the interpretation of the IVDR and its complications. Clin Chem Lab Med. 2020. https://doi.org/10.1515/cclm-2020-1384[publi shedOnlineFirst:2021/02/09].

8. Barberis M. In vitro diagnostic medical device regulation (IVDR): the end of laboratory developed tests (LDT)? Pathol J Ital Soc Anat Pathol Diagn Cytopathol. 2021;113(2):68-9. https://doi.org/ 10.32074/1591-951X-237.

9. Commission E. Medical Devices-EUDAMED European Commission website 2020. https://ec.europa.eu/health/md_eudamed/ overview_en. Accessed 05 Oct 2020.

10. Rubinstein WS, Maglott DR, Lee JM, et al. The NIH genetic testing registry: a new, centralized database of genetic tests to enable access to comprehensive information and improve transparency. Nucleic Acids Res. 2013;41(Database issue):D925-35. https:// doi.org/10.1093/nar/gks1173.

11. Gökmen-Polar Y. Overview of PCR-based technologies and multiplexed gene analysis for biomarker studies. In: Badve S, Kumar GL, editors. Predictive biomarkers in oncology: applications in precision medicine. Cham: Springer International Publishing; 2019. p. 63-73.

12. Walczak M, Skrzypczak-Zielinska M, Plucinska M, et al. Longrange PCR libraries and next-generation sequencing for pharmacogenetic studies of patients treated with anti-TNF drugs. Pharmacogenomics J. 2019;19(4):358-67. https://doi.org/10.1038/ s41397-018-0058-9.

13. Cascella R, Strafella C, Ragazzo M, et al. Direct PCR: a new pharmacogenetic approach for the inexpensive testing of HLAB*57:01. Pharmacogenomics J. 2015;15(2):196-200. https://doi. org/10.1038/tpj.2014.48.

14. Zheng L-J, Liu N, Yang K, et al. Clinical application and importance of one-step human CYP2C19 genotype detection. J Int Med Res. 2018;46(12):4965-73. https://doi.org/10.1177/0300060518 787718.

15. Gürtler C, Laible M, Schwabe W, et al. Transferring a quantitative molecular diagnostic test to multiple real-time quantitative PCR platforms. J Mol Diagn. 2018;20(4):398-414. https://doi. org/10.1016/j.jmoldx.2018.02.004 (published Online First: 2018/04/07). 
16. Markou A, Tzanikou E, Ladas I, et al. Nuclease-assisted minor allele enrichment using overlapping probes-assisted amplification-refractory mutation system: an approach for the improvement of amplification-refractory mutation system-polymerase chain reaction specificity in liquid biopsies. Anal Chem. 2019;91(20):13105-11. https://doi.org/10.1021/acs.analchem. $9 \mathrm{~b} 03325$.

17. Stuppia L, Antonucci I, Palka G, et al. Use of the MLPA assay in the molecular diagnosis of gene copy number alterations in human genetic diseases. Int J Mol Sci. 2012;13(3):3245-76. https://doi. org/10.3390/ijms 13033245 (published Online First: 03/08).

18. Frayling IM, Monk E, Butler R. PCR-based methods for mutation detection. In: Coleman WB, Tsongalis GJ, editors. Molecular Diagnostics: For the Clinical Laboratorian. Totowa: Humana Press; 2005. p. 65-74.

19. Murphy J, Bustin SA. Reliability of real-time reverse-transcription PCR in clinical diagnostics: gold standard or substandard? Expert Rev Mol Diagn. 2009;9(2):187-97. https://doi.org/10.1586/14737 159.9.2.187 (published Online First: 2009/03/21).

20. Letovanec I, Finn S, Zygoura P, et al. Evaluation of NGS and RTPCR methods for ALK rearrangement in european nsclc patients: results from the european thoracic oncology platform lungscape project. J Thorac Oncol. 2018;13(3):413-25. https://doi.org/10. 1016/j.jtho.2017.11.117 (published Online First: 2017/12/02).

21. Mamotte CDS. Genotyping of single nucleotide substitutions. Clin Biochem Rev. 2006;27(1):63-75.

22. Erali M, Wittwer CT. High resolution melting analysis for gene scanning. Methods. 2010;50(4):250-61. https://doi.org/10.1016/j. ymeth.2010.01.013 (published Online First: 01/18).

23. Montgomery J, Wittwer CT, Kent JO, et al. Scanning the cystic fibrosis transmembrane conductance regulator gene using highresolution DNA melting analysis. Clin Chem. 2007;53(11):18918. https://doi.org/10.1373/clinchem.2007.092361 (published Online First: 2007/09/25).

24. Ota M, Fukushima H, Kulski JK, et al. Single nucleotide polymorphism detection by polymerase chain reaction-restriction fragment length polymorphism. Nat Protoc. 2007;2(11):2857-64. https://doi.org/10.1038/nprot.2007.407 (published Online First: 2007/11/17).

25. Kawada I, Soejima K, Watanabe H, et al. An alternative method for screening EGFR mutation using RFLP in non-small cell lung cancer patients. J Thoracic Oncol. 2008;3(10):1096-103. https:// doi.org/10.1097/JTO.0b013e318186fadd (published Online First: 2008/10/02).

26. Schimanski CC, Linnemann U, Berger MR. Sensitive detection of K-ras mutations augments diagnosis of colorectal cancer metastases in the liver. Cancer Res. 1999;59(20):5169-75 (published Online First: 1999/10/28).

27. Evans J, Swart M, Soko N, et al. A Global Health Diagnostic for personalized medicine in resource-constrained world settings: a simple PCR-RFLP method for genotyping CYP2B6 g.15582C $>$ T and science and policy relevance for optimal use of antiretroviral drug Efavirenz. OMICS. 2015;19(6):332-38. https://doi.org/10. 1089/omi.2015.0039.

28. Vu NP, Nguyen HTT, Tran NTB, et al. CYP2C19 genetic polymorphism in the Vietnamese population. Ann Hum Biol. 2019;46(6):491-7. https://doi.org/10.1080/03014460.2019.16877 50 (published Online First: 2019/11/27).

29. Chretien AS, Harlé A, Meyer-Lefebvre M, et al. Optimization of routine KRAS mutation PCR-based testing procedure for rational individualized first-line-targeted therapy selection in metastatic colorectal cancer. Cancer Med. 2013;2(1):11-20. https://doi.org/ 10.1002/cam4.47 (published Online First: 2013/10/18).

30. Breyer JP, Smith JR. Practical genotyping by single-nucleotide primer extension. Biol Methods Protoc. 2020. https://doi.org/10. 1093/biomethods/bpaa002.
31. Litos IK, Ioannou PC, Christopoulos TK, et al. Genotyping of single-nucleotide polymorphisms by primer extension reaction in a dry-reagent dipstick format. Anal Chem. 2007;79(2):395-402. https://doi.org/10.1021/ac061729e (published Online First: 2007/01/16).

32. Ross P, Hall L, Smirnov I, et al. High level multiplex genotyping by MALDI-TOF mass spectrometry. Nat Biotechnol. 1998;16(13):1347-51. https://doi.org/10.1038/4328 (published Online First: 1998/12/16)

33. Tost J, Gut IG. Genotyping single nucleotide polymorphisms by MALDI mass spectrometry in clinical applications. Clin Biochem. 2005;38(4):335-50. https://doi.org/10.1016/j.clinbiochem.2004. 12.005 (published Online First: 2005/03/16).

34. Su KY, Kao JT, Ho BC, et al. Implementation and quality control of lung cancer EGFR genetic testing by MALDI-TOF mass spectrometry in Taiwan Clinical Practice. Sci Rep. 2016;6:30944. https://doi.org/10.1038/srep30944 (published Online First: 2016/08/03).

35. Liu J, Xu Z, Li Y, et al. Comparison between MassARRAY and pyrosequencing for $\mathrm{CYP} 2 \mathrm{C} 19$ and $\mathrm{ABCB} 1$ gene variants of clopidogrel efficiency genotyping. Mol Membr Biol. 2019;35(1):1-8. https://doi.org/10.1080/09687688.2019.1597194 (published Online First: 2019/03/28).

36. Bray MS, Boerwinkle E, Doris PA. High-throughput multiplex SNP genotyping with MALDI-TOF mass spectrometry: practice, problems and promise. Hum Mutat. 2001;17(4):296-304. https:// doi.org/10.1002/humu.27 (published Online First: 2001/04/11).

37. Schouten JP, McElgunn CJ, Waaijer R, et al. Relative quantification of 40 nucleic acid sequences by multiplex ligation-dependent probe amplification. Nucleic Acids Res. 2002;30(12):e57-e57. https://doi.org/10.1093/nar/gnf056.

38. Katsanis SH, Katsanis N. Molecular genetic testing and the future of clinical genomics. Nat Rev Genet. 2013;14(6):415-26. https:// doi.org/10.1038/nrg3493.

39. Butz H, Patócs A. Brief summary of the most important molecular genetic methods (PCR, qPCR, microarray, next-generation sequencing, etc.). Exp Suppl. 2019;111:33-52. https://doi. org/10.1007/978-3-030-25905-1_4 (published Online First: 2019/10/08).

40. Labuda D, Krajinovic M, Richer C, et al. Rapid detection of CYP1A1, CYP2D6, and NAT variants by multiplex polymerase chain reaction and allele-specific oligonucleotide assay. Anal Biochem. 1999;275(1):84-92. https://doi.org/10.1006/abio.1999. 4293[publishedOnlineFirst:1999/11/05].

41. Dwivedi S, Purohit P, Misra R, et al. Diseases and molecular diagnostics: a step closer to precision medicine. Indian J Clin Biochem. 2017;32(4):374-98. https://doi.org/10.1007/ s12291-017-0688-8.

42. Harrington CT, Lin EI, Olson MT, et al. Fundamentals of pyrosequencing. Arch Pathol Lab Med. 2013;137(9):1296-303. https:// doi.org/10.5858/arpa.2012-0463-RA (published Online First: 2013/09/03).

43. Davidson CJ, Zeringer E, Champion KJ, et al. Improving the limit of detection for Sanger sequencing: a comparison of methodologies for KRAS variant detection. Biotechniques. 2012;53(3):1828. https://doi.org/10.2144/000113913 (published Online First: 2012/09/12)

44. Mardis ER. Next-generation DNA sequencing methods. Annu Rev Genom Hum Genet. 2008;9:387-402. https://doi.org/10. 1146/annurev.genom.9.081307.164359 (published Online First: 2008/06/26).

45. Gu W, Miller S, Chiu CY. Clinical metagenomic next-generation sequencing for pathogen detection. Annu Rev Pathol. 2019;14:319-38. https://doi.org/10.1146/annurev-pathmechdis012418-012751 (published Online First: 2018/10/26). 
46. Garrido-Cardenas JA, Garcia-Maroto F, Alvarez-Bermejo JA, et al. DNA sequencing sensors: an overview. Sensors (Basel). 2017;17(3):588. https://doi.org/10.3390/s17030588.

47. Chen $\mathrm{M}$, Zhao H. Next-generation sequencing in liquid biopsy: cancer screening and early detection. Hum Genom. 2019;13(1):34. https://doi.org/10.1186/s40246-019-0220-8.

48. Kastrisiou M, Zarkavelis G, Pentheroudakis G, et al. Clinical application of next-generation sequencing as a liquid biopsy technique in advanced colorectal cancer: a trick or a treat? Cancers (Basel). 2019. https://doi.org/10.3390/cancers11101573 (published Online First: 2019/10/19).

49. Heeke S, Hofman V, Ilié M, et al. Prospective evaluation of NGSbased liquid biopsy in untreated late stage non-squamous lung carcinoma in a single institution. J Transl Med. 2020;18(1):87. https://doi.org/10.1186/s12967-020-02259-2 (published Online First: 2020/02/19).

50. Papadopoulou E, Tsoulos N, Tsantikidi K, et al. Clinical feasibility of NGS liquid biopsy analysis in NSCLC patients. PLoS ONE. 2019;14(12):e0226853. https://doi.org/10.1371/journal.pone. 0226853 (published Online First: 2019/12/21).

51. Bonneville R, Krook MA, Chen HZ, et al. Detection of microsatellite instability biomarkers via next-generation sequencing. Methods in Mol Biol. 2020;2055:119-32. https://doi.org/10.1007/ 978-1-4939-9773-2_5 (published Online First: 2019/09/11).

52. Fumet JD, Truntzer C, Yarchoan M, et al. Tumour mutational burden as a biomarker for immunotherapy: current data and emerging concepts. Eur J Cancer. 2020;131:40-50. https://doi.org/10. 1016/j.ejca.2020.02.038 (published Online First: 2020/04/13).

53. Munkongdee T, Chen P, Winichagoon $\mathrm{P}$, et al. Update in laboratory diagnosis of thalassemia. Front Mol Biosci. 2020;7:74-74. https://doi.org/10.3389/fmolb.2020.00074.

54. Pareek CS, Smoczynski R, Tretyn A. Sequencing technologies and genome sequencing. J Appl Genet. 2011;52(4):413-35. https:// doi.org/10.1007/s13353-011-0057-x (published Online First: 2011/06/24).

55. Bakker E. Is the DNA sequence the gold standard in genetic testing? Quality of molecular genetic tests assessed. Clin Chem. 2006;52(4):557-8. https://doi.org/10.1373/clinchem.2005.066068 (published Online First: 2006/04/06).

56. Illumina. Illumina sequencing platforms: Illumina; 2020. https:// www.illumina.com/systems/sequencing-platforms.html. Accessed 14 Dec 2020.

57. Illumina. Whole-genome sequencing power: Illumina; 2020. https://www.illumina.com/systems/sequencing-platforms/hiseqx.html. Accessed 14 Dec 2020.

58. Illumina. High performance, low cost genomics. 2020. https:// www.illumina.com/systems/sequencing-platforms/hiseq-30004000.html. Accessed 14 Dec 2020.

59. Rossi G, Ignatiadis M. Promises and pitfalls of using liquid biopsy for precision medicine. Can Res. 2019;79(11):2798-804. https://doi.org/10.1158/0008-5472.Can-18-3402 (published Online First: 2019/05/22).

60. Halvaei S, Daryani S, Eslami-S Z, et al. Exosomes in cancer liquid biopsy: a focus on breast cancer. Mol Ther Nucleic Acids. 2018;10:131-41. https://doi.org/10.1016/j.omtn.2017.11.014 (published Online First: 2017/12/01).

61. Qiu J, Xu J, Zhang K, et al. refining cancer management using integrated liquid biopsy. Theranostics. 2020;10(5):2374-84. https://doi.org/10.7150/thno.40677.

62. Girolami F, Frisso G, Benelli M, et al. Contemporary genetic testing in inherited cardiac disease: tools, ethical issues, and clinical applications. J Cardiovasc Med (Hagerstown). 2018;19(1):1-11. https://doi.org/10.2459/jcm.0000000000 000589[publishedOnlineFirst:2017/11/28].

63. Baudhuin LM, Lagerstedt SA, Klee EW, et al. Confirming variants in next-generation sequencing panel testing by sanger sequencing. J Mol Diagn. 2015;17(4):456-61. https://doi.org/ 10.1016/j.jmoldx.2015.03.004[publishedOnlineFirst:2015/05/ 12].

64. Kerkhof J, Schenkel LC, Reilly J, et al. Clinical validation of copy number variant detection from targeted next-generation sequencing Panels. J Mol Diagn. 2017;19(6):905-20. https://doi.org/10. 1016/j.jmoldx.2017.07.004.

65. Agency EM. Keytruda: EPAR-Product information Annex I. Official website of the European Union: European Medicines Agency. 2021.

66. Agency EM. Herceptin: EPAR—product information Annex I. Official website of the European Union: European Medicines Agency. 2021.

67. Javitt G, Katsanis S, Scott J, et al. Developing the blueprint for a genetic testing registry. Public Health Genom. 2010;13(2):95105. https://doi.org/10.1159/000226593 (published Online First: 06/29).

68. Yang L, Ijaz I, Cheng J, et al. Evaluation of amplification refractory mutation system (ARMS) technique for quick and accurate prenatal gene diagnosis of CHM variant in choroideremia. Appl Clin Genet. 2017;11:1-8. https://doi.org/10.2147/TACG.S1443 83.

69. Little S. Amplification-refractory mutation system (ARMS) analysis of point mutations. Curr Protoc Human Genet.2001. https:// doi.org/10.1002/0471142905.hg0908s07 (Chapter 9:Unit 9 8; published Online First: 2008/04/23).

70. Suo W, Shi X, Xu S, et al. Towards low cost, multiplex clinical genotyping: 4-fluorescent Kompetitive Allele-Specific PCR and its application on pharmacogenetics. PLoS ONE. 2020;15(3):e0230445-e230545. https://doi.org/10.1371/journal. pone. 0230445 .

71. Shitaye G, Gadisa E, Grignard L, et al. Low and heterogeneous prevalence of glucose-6-phosphate dehydrogenase deficiency in different settings in Ethiopia using phenotyping and genotyping approaches. Malar J. 2018;17(1):281. https://doi.org/10.1186/ s12936-018-2437-8.

72. He C, Holme J, Anthony J. SNP genotyping: the KASP assay. Methods Mol Biol. 2014;1145:75-86. https://doi.org/10.1007/ 978-1-4939-0446-4_7 (published Online First: 2014/05/13).

73. Mann K, Ogilvie CM. QF-PCR: application, overview and review of the literature. Prenat Diagn. 2012;32(4):309-14. https://doi.org/ 10.1002/pd.2945[publishedOnlineFirst:2012/04/03].

74. Konjhodzic R, Dervovic E, Kurtovic-Basic I, et al. Use of quantitative fluorescent polymerase chain reaction (QF PCR) in prenatal diagnostic of fetal aneuploidies in a 17 month period in parallel with karyotyping. Acta Inform Med. 2014;22(2):86-8. https://doi. org/10.5455/aim.2014.22.86-88.

75. Illumina. Understanding the genetic code: Illumina; 2020. https:// www.illumina.com/techniques/sequencing/dna-sequencing.html. Accessed 17 Dec 2020.

76. Scientific TF. Ion GeneStudio S5 Next-Generation Sequencing Series Specifications: Thermo Fisher Scientific; 2020. https:// www.thermofisher.com/de/de/home/life-science/sequencing/ next-generation-sequencing/ion-torrent-next-generation-seque ncing-workflow/ion-torrent-next-generation-sequencing-runsequence/ion-s5-ngs-targeted-sequencing/ion-s5-specifications. html. Accessed 01 Dec 2020.

77. Scientific TF. Ion GeneStudio S5 Series Systems: Thermo Fisher Scientific; 2020. https://assets.thermofisher.com/TFS-Assets/ CSD/brochures/ion-genestudio-s5-ngs-system-brochure.pdf. Accessed 04 Dec 2020.

78. Scientific TF. Ion semiconductor sequencing uniquely enables both accurate long reads and paired-end sequencing: Thermo Fisher Scientific; 2020. http://tools.thermofisher.com/content/ sfs/brochures/cms_098680.pdf. Accessed 01 Dec 2020. 
79. Scientific TF. Ion S5 and Ion S5 XL Systems: Thermo Fisher Scientific; 2020. http://tools.thermofisher.com/content/sfs/broch ures/Ion-S5-S5XL-Brochure.pdf.. Accessed 01 Dec 2020.

80. Biosciences P. SMRT Sequencing: Pacific Biosciences; 2020. https://www.pacb.com/smrt-science/smrt-sequencing/.. Accessed 12 Dec 2020.

81. Ardui S, Ameur A, Vermeesch JR, et al. Single molecule realtime (SMRT) sequencing comes of age: applications and utilities for medical diagnostics. Nucleic Acids Res. 2018;46(5):2159-68. https://doi.org/10.1093/nar/gky066.
82. Technologies ON. MinION: Oxford Nanopore Technologies; 2020. https://nanoporetech.com/products/minion.. Accessed 12 Dec 2020.

83. Kono N, Arakawa K. Nanopore sequencing: Review of potential applications in functional genomics. Dev Growth Differ. 2019;61(5):316-26. https://doi.org/10.1111/dgd.12608[publi shedOnlineFirst:2019/05/01]. 